\title{
A hydroclimatic regionalization of central Mongolia as inferred from tree rings
}

\author{
Caroline Leland $^{\mathrm{a}, \mathrm{b}, *}$, Neil Pederson ${ }^{\mathrm{b}}$, Amy Hessl $^{\mathrm{a}}$, Baatarbileg Nachin ${ }^{\mathrm{b}, \mathrm{c}}$, Nicole Davi ${ }^{\mathrm{b}}$, \\ Rosanne D’Arrigo ${ }^{b}$, Gordon Jacoby ${ }^{b}$
}

a Department of Geology and Geography, West Virginia University, P.O. Box 6300, Morgantown, WV 26506, USA

b Tree-Ring Laboratory, Lamont-Doherty Earth Observatory, P.O. Box 1000, 61 Route 9W, Palisades, NY 10964, USA

${ }^{\mathrm{c}}$ Tree-Ring Laboratory, Department of Forest Sciences, National University of Mongolia, Ulaanbaatar, Mongolia

\section{A R T I C L E I N F O}

\section{Article history:}

Received 10 January 2012

Accepted 12 November 2012

\section{Keywords:}

Mongolia

Dendroclimatology

RPCA

Climate regions

\begin{abstract}
A B S T R A C T
In arid and semi-arid regions of the world, such as Mongolia, the future of water resources under a warming climate is of particular concern. The influence of increasing temperatures on precipitation is difficult to predict because precipitation trends in coming decades could have a high degree of spatial variability. In this study, we applied a rotated principal component analysis (RPCA) to a network of 20 treering chronologies across central Mongolia from 1790 to 1994 to evaluate spatial hydroclimatic variability and to place recent variability in the context of the past several centuries. The RPCA results indicate that the network consists of four tree-growth anomaly regions, which were found to be relatively stable through time and space. Correlation analyses reveal spatial linkages between the tree-growth anomalies and instrumental data, where annual streamflow variability was strongly associated with tree-growth anomalies from their respective regions from 1959 to $1994(r=0.52-0.64, p<0.05)$. This study highlights the extent of spatial variability in hydroclimate across central Mongolia and emphasizes the value of using tree-ring networks in locations with limited instrumental records.
\end{abstract}

(c) 2013 Elsevier GmbH. All rights reserved.

\section{Introduction}

Climate change models project increasing temperatures across Asia in coming decades with the most pronounced warming occurring in northern and central Asia (Christensen et al., 2007). Consistent with these predictions, instrumental records from Mongolia suggest that average temperatures have been generally increasing since the 1940s (Batima et al., 2005). Warming temperatures can influence hydrology by increasing evaporation rates, enhancing water retention in the atmosphere, changing the timing of snowmelt, and altering the severity of floods and droughts (Trenberth et al., 2003). The multiple impacts of increasing temperatures on hydrology, in combination with the local nature of precipitation (Tebaldi et al., 2006), has led to great uncertainty in predicting future hydrologic change at fine-resolutions in Asia (Christensen et al., 2007), including Mongolia (Sato et al., 2007a).

Increasing temperatures and uncertainty in regional precipitation trends have led to increased concern over the availability of water in the future. In arid and semi-arid regions, like Mongolia,

\footnotetext{
* Corresponding author. Present address: Tree-Ring Laboratory, Lamont-Doherty Earth Observatory, P.O. Box 1000, 61 Route 9W, Palisades, New York 10964, USA. Tel.: +1 703786 1148; fax: +1 8453658150 .

E-mail address: carolineleland@gmail.com (C. Leland).
}

the impacts of drought could be devastating. Pastoralism and agriculture are a major component of Mongolian culture, economy, and livelihood (Johnson et al., 2006). Therefore, the frequency and intensity of droughts are important considerations in determining the susceptibility of Mongolians to climatic extremes. For example, the drought of 1999-2002 was linked to significant losses of livestock and had negative impacts on local economies (Siurua and Swift, 2002; Batima et al., 2005). The social and economic impacts of drought across Mongolia warrant a better understanding of how hydroclimate, or moisture availability, has varied in the past relative to recent decades.

Although instrumental records provide a basic assessment of recent climate trends across Mongolia (Batima et al., 2005; Endo et al., 2006), the records are short (typically 20-60 years in length) and spatially limited. Instrumental records are scarce or nonexistent in remote regions, and few records predate the 1940s. Several climate reconstructions have been carried out by those involved with the Mongolian American Tree-ring Project (MATRIP), a research collaboration between scientists from Lamont-Doherty Earth Observatory and Mongolia, to assess climatic variability prior to instrumental records and to place recent climate anomalies in a historical context. Both hydrometeorological (Pederson et al., 2001, 2012; Davi et al., 2006) and drought reconstructions (Davi et al., 2009, 2010) produced by MATRIP highlight the complexity of hydroclimate across Mongolia and emphasize climatic variability between regions. 
Networks of tree-ring chronologies have been used to assist the development of climate reconstructions and to assess spatial patterns of climatic variability. Several studies implement Principal Components Analysis (PCA) to identify regions of co-variation in tree-growth (i.e., tree-growth anomalies) (e.g., LaMarche and Fritts, 1971; Brubaker, 1980; Meko et al., 1993; Watson and Luckman, 2001). Tree-growth anomalies represent unique growth patterns and can typically be linked to one or several drivers of growth, often specific climate variables. Studies examining tree-growth anomalies have been conducted on several different spatial scales. On a broad scale, Meko et al. (1993) delineated tree-growth anomaly regions across the continental United States and discovered that the regions generally coincided with drought regions defined by a PCA of Palmer Drought Severity Index (PDSI) values. Similar methods were applied by Fang et al. (2010) for reconstructing spatial droughts in central High Asia. Chronology networks spanning smaller, sub-regional scales in North America have also been valuable in uncovering local variation in climate (e.g., Brubaker, 1980; Watson and Luckman, 2001). In this study, we take a fine-scale approach in investigating spatial characteristics of tree-growth anomalies. This approach is particularly important for understanding local climatic variability in central Mongolia, and no studies have yet examined tree-growth anomalies at an equivalent, regional spatial scale in this part of Asia.

Here, we present a network of 20 tree-ring chronologies to determine the extent of hydroclimatic variability in central Mongolia. Specifically, we: (1) assess spatial and temporal characteristics of tree-growth anomalies, (2) determine the stability of tree-growth anomalies over time, and (3) evaluate the potential hydroclimatic signal associated with the tree-growth anomalies. This analysis seeks to identify hydroclimatic regions that have not yet been fully explored from a paleoclimatic perspective to guide further efforts in developing climate reconstructions for central Mongolia.

\section{Materials and methods}

\section{Tree-ring network}

We compiled a network of 20 tree-ring chronologies from central Mongolia, spanning $46^{\circ} 47^{\prime} \mathrm{N}$ to $50^{\circ} 09^{\prime} \mathrm{N}$ latitude and $99^{\circ} 52^{\prime}$ E to $111^{\circ} 41^{\prime}$ E longitude, for this study (Table 1, Fig. 1). Elevations range from $\sim 650 \mathrm{~m}$ to $\sim 2000 \mathrm{~m}$, and the network includes chronologies from the Khangai and Khentyi Mountain ranges. The study area is located mostly within the forest-steppe ecotone; therefore, forests are often limited to north-facing slopes. The uneven distribution of forest cover resulted in an irregular distribution of chronologies across the network. Similarly, the tree species represented in the chronologies, Scots Pine (P. sylvestris), Siberian Pine ( $P$. sibirica), and Siberian Larch ( $L$. sibirica), are not evenly spread across the network due to regional species distributions. We used these tree species in this study because they provide the longest known records of tree growth in the study area.

Of the 20 chronologies we used in this study, 11 chronologies were developed through MATRIP. Many of the MATRIP chronologies were used in previous hydroclimatic reconstructions and are known to be drought-sensitive (Pederson et al., 2001; Davi et al., 2006, 2010). We collected nine additional tree-ring chronologies in 2009 and 2010. Most of these chronologies were collected from classic moisture-limited sites with steep slopes or well-drained substrate (Fritts, 1976). We targeted old trees at each site(Swetnam and Brown, 1992; Pederson, 2010), and extracted two increment cores per tree if possible. In some cases where trees had significant heartrot, we extracted only one increment core. This was not a serious limitation as tree replication is often more useful than core replication (Fritts, 1976).

In the laboratory, we prepared increment cores of the new collections following standard dendrochronological methods (Stokes and Smiley, 1968). We first visually crossdated all tree cores within a site. We measured growth rings to at least an accuracy of $0.001 \mathrm{~mm}$ on a Velmex measuring stage, and then we verified all visual crossdating with the quality control program COFECHA (Holmes, 1983).

We developed site chronologies using established standardization techniques with the program ARSTAN (Cook, 1985; Cook and Krusic, 2011). The standardization process removes non-climatic variability in each tree-ring series and averages the detrended ringwidths of all series from a site to reduce the noise of individual trees (Fritts, 1976). We detrended all of the series with a linear or negative exponential curve to remove allometric trends in ring-width, and the heteroscedastic variance of each series was stabilized with a data-adaptive power transformation of the residuals (Cook and Peters, 1997; Esper et al., 2003). For trees in closed-canopy forests, standardizing with a flexible curve may help reduce growth patterns related to disturbance and competition (Cook and Peters, 1981; Pederson et al., 2004). Therefore, series with obvious suppression and release patterns in ring-widths (sensu Lorimer and Frelich, 1989) were detrended again with a conservative Friedman supersmoother curve having an $\alpha$ parameter between 6 and 9 (Friedman, 1984; Buckley et al., 2010).

In order to retain low-frequency variability within the treering data we used standard and ARSTAN chronologies for all analyses. Standard chronologies were chosen for sites exhibiting open-canopy conditions, as tree-growth patterns from these sites typically display classic negative exponential or linear trends. For closed-canopy sites, we retained the ARSTAN chronology, which pools the autoregressive properties common to many series from the site in order to mitigate effects of non-synchronous and endogenous disturbance trends (Cook, 1985). It should be noted that results were not significantly different when using residual (i.e., prewhitened) chronologies. This suggests that potential species differences in serial autocorrelation between chronologies are not an important factor in the presented results. Variances of all chronologies were stabilized with either the $r$-bar weighted method or one-third smoothing spline option in the program ARSTAN (Cook and Krusic, 2011).

The expressed population signal (EPS) statistic was calculated for each chronology in 50-year segments of overlapping 25-years to determine a common period for all chronologies in the network. The EPS gauges the signal-to-noise ratio of a chronology over time and it is a useful metric for assessing chronology strength (Cook and Kairiukstis, 1990). An EPS of 0.85 has been proposed as an appropriate cut-off criterion for climate reconstructions (Wigley et al., 1984). Therefore, we established the common period as 1790-1994 since most chronologies maintain a between-tree EPS of 0.85 for that period of time, with the only exceptions being Tujyin Nars (TNC) and Bugant (BG), which drop to $\sim 0.75$ and $\sim 0.80$ around 1790 , respectively. These chronologies were retained because, despite their marginally lower EPS values, their locations are valuable components of the network.

\section{Instrumental data}

We used streamflow data to investigate the relationship between tree-growth anomalies and hydroclimate. The instrumental data were collected from three different stream gauges within the study region: the Selenge (1945), Yeruu (1959), and Kherlen (1959) Rivers (Fig. 1). The years in parentheses indicate how far each instrumental record extends back in time. We averaged the 
Table 1

List of site chronologies in the tree-ring network.

\begin{tabular}{|c|c|c|c|c|c|c|}
\hline Chronology & Code & Alt (m) & Species & \# Trees & Years & CRN type \\
\hline Bugant $^{\mathrm{a}}$ & BG & 1027 & P. sylvestris & 19 & $1730-2008$ & ARS \\
\hline Dadal & DR & 1020 & P. sibirica & 15 & 1704-2001 & STD \\
\hline Delger Khan Uula & $\mathrm{DKH}$ & 1247 & P. sylvestris & 13 & 1710-2009 & ARS \\
\hline Dulaankhan ${ }^{\mathrm{a}}$ & DKN & 1180 & P. sylvestris & 20 & $1653-2008$ & STD \\
\hline Inferno Ridge & IR & 900 & P. sibirica & 19 & 1692-1996 & ARS \\
\hline Khorgo Lava Larch & KLL & 2060 & L. sibirica & 39 & $1340-2000$ & STD \\
\hline Khorgo Lava Pine ${ }^{a}$ & KLP & 2077 & P. sibirica & 13 & $1422-2009$ & STD \\
\hline Manzshir Hiid & $\mathrm{MH}$ & 1755 & P. sibirica & 8 & 1505-1994 & ARS \\
\hline Narstain Davaa ${ }^{\mathrm{a}}$ & NTD & 1548 & P. sylvestris & 11 & 1740-2008 & ARS \\
\hline Onon Gol & ONG & 1012 & L. sibirica & 16 & $1576-2001$ & ARS \\
\hline Orkhon Gol Hurhree ${ }^{a}$ & $\mathrm{OGH}$ & 1829 & L. sibirica & 15 & 1503-2009 & STD \\
\hline Suulchyin Medee & SM & 1419 & L. sibirica & 15 & 1557-2002 & STD \\
\hline Shaamar Manhan Nars ${ }^{\mathrm{a}}$ & SMN & 650 & P. sylvestris & 9 & 1770-2008 & ARS \\
\hline Terelj & $\mathrm{TJ}$ & 1669 & L. sibirica & 16 & 1590-2002 & STD \\
\hline Tujyin Nars ${ }^{\mathrm{a}}$ & TNC & 750 & P. sylvestris & 12 & $1731-2008$ & ARS \\
\hline Undur Ulaan & UU & 1545 & L. sibirica & 15 & 1510-2002 & STD \\
\hline Urgun Nars & UN & 1070 & P. sylvestris & 15 & 1651-1996 & STD \\
\hline Zurkh Uula & ZHU & 1228 & P. sylvestris & 14 & 1714-2009 & STD \\
\hline Zuun Mod & $\mathrm{ZM}$ & 1415 & L. sibirica & 26 & $1582-2000$ & STD \\
\hline Zuun Salaa Mod & ZSM & 1900 & L. sibirica & 20 & $1513-2001$ & STD \\
\hline
\end{tabular}

a The newest chronology collections.

June-August values of streamflow for each year to create an annual time-series for comparison against the tree-growth anomalies. Streamflow data was preferred over PDSI data (Dai et al., 2004) for this study because they provide site-specific and measured values of hydroclimate that have direct application and importance to Mongolian livelihoods.

\section{Methods}

RPCA and the development of regional time series

We performed a varimax rotated principal component analysis (RPCA) over the 1790-1994 common period of all chronologies to detect tree-growth anomalies across the network. We applied an S-mode PCA using the correlation matrix of the full network, in which the chronologies were the variables and the individual years were the observations, and all components with an eigenvalue $>1$ were retained for the varimax rotation. Each of the resulting factors represents an individual tree-growth anomaly that is present within the network of chronologies. Therefore, chronologies with a high loading on a particular factor are associated with the same tree-growth anomaly and are expected to co-vary similarly over time. The varimax rotation eases interpretation of results as the variables load strongly on to one or few orthogonal factors (Richman, 1986). Some studies have suggested that the orthogonality requirement of a varimax rotation might not be realistic (Meko et al., 1993; Cook et al., 1999), and that oblique rotations provide more stable results (White et al., 1991). However, we found that an oblique rotation of the dataset, which allows some correlation between factors, did not alter the general outcome.

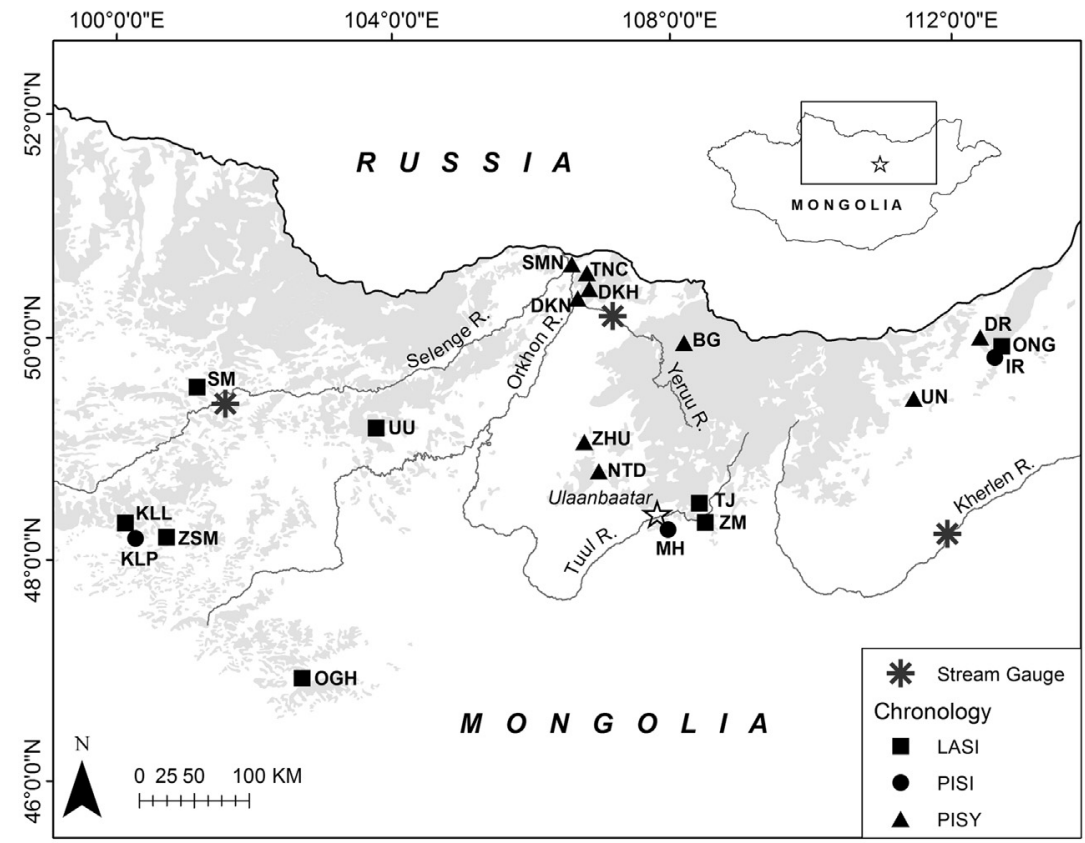

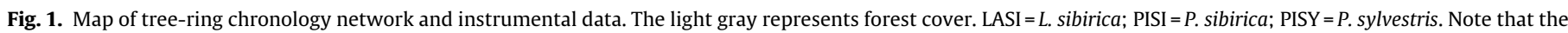
Kherlen streamflow data used in this study is from the Underkhaan gauge, which is different from the Choibalsan streamflow gauge used in Pederson et al. (2001). 

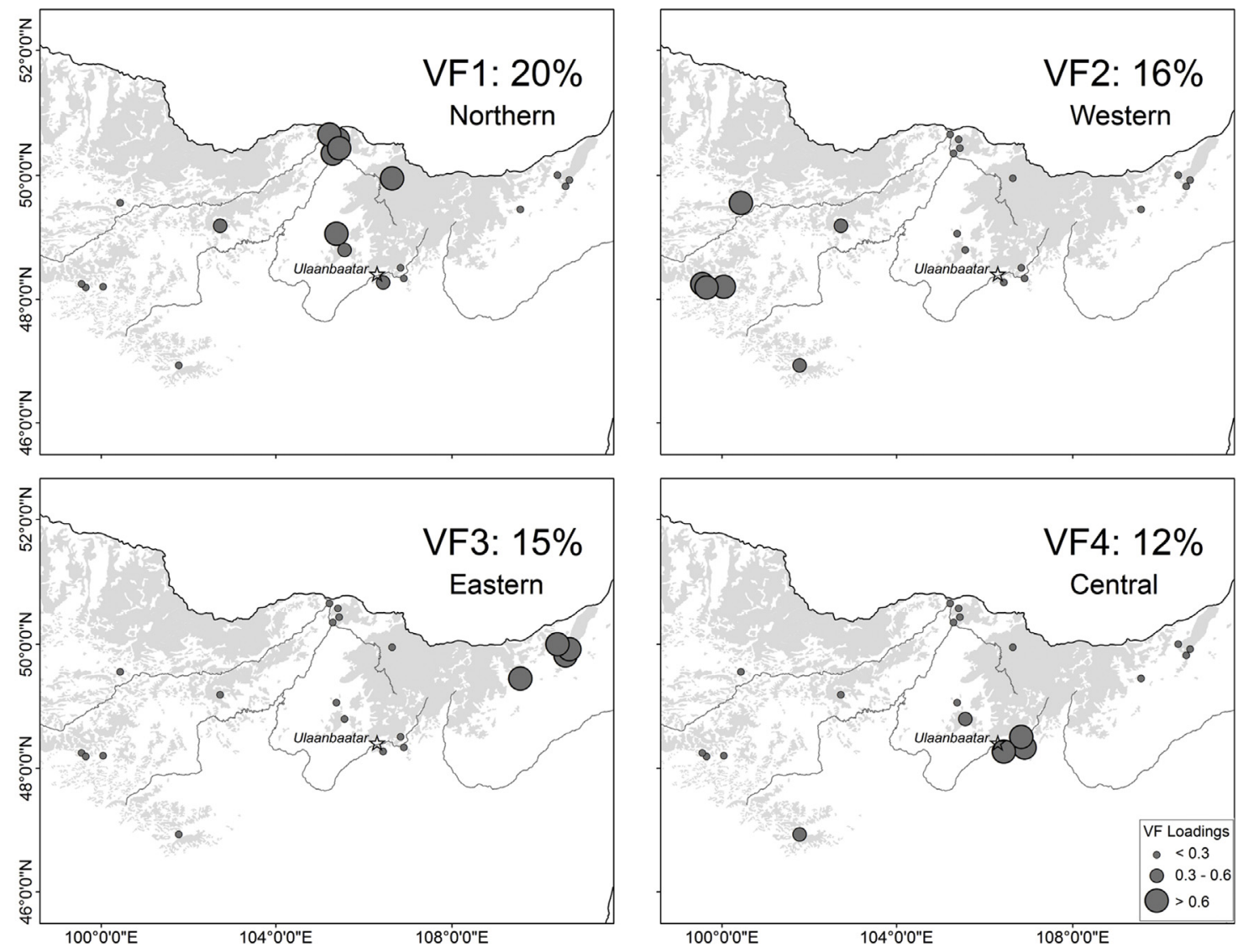

Fig. 2. Maps showing loadings for each varimax factor in the full period (1790-1994).

Chronology loadings for each factor were mapped in order to investigate the spatial characteristics of the tree-growth anomalies. Chronologies sharing a common growth anomaly are typically clustered into 'regions', which suggests that similar variables drive growth (LaMarche and Fritts, 1971; Brubaker, 1980; Watson and Luckman, 2001). Here, each chronology was assigned to a treegrowth anomaly, and corresponding region, based on its RPCA factor loadings; the factor that each chronology loaded highest onto determined the tree-growth anomaly (region) to which it was assigned. Then, we produced an individual time-series for each tree-growth anomaly by performing an unrotated PCA only on the chronologies assigned to each region. The first component scores (PC1) for each region were retained as a means of summarizing annual growth from 1790 to 1994, where negative scores indicate years of below-average growth and positive scores indicate above-average growth (Brubaker, 1980). The PC1 scores from the unrotated PCAs were preferred over the factor scores from the original RPCA so that the regional time-series would not be forced into orthogonality.

\section{Testing the stability of tree-growth anomaly regions}

The temporal stability of the tree-growth anomaly regions was tested by running separate RPCAs on temporal subsets of the common period (Watson and Luckman, 2001). The common period was split into roughly equal halves (1790-1891 for the early period; 1892-1994 for the late period). For each temporal subset, an RPCA was conducted on the full 20-chronology network using the same methods as detailed for the full common period analysis. The chronology loadings were mapped for each factor, and all chronologies were assigned to a tree-growth anomaly region based on their loadings. By comparing the spatial results of chronology loadings for the temporal subsets with the full common period analysis, we could gauge the relative stability of the tree-growth anomaly regions through time.

The spatial stability of the tree-growth anomaly regions over the full common period (1790-1994) was then evaluated with a reduced dataset analysis (similar to Watson and Luckman, 2001). An uneven spatial distribution of chronology sites can potentially bias the results of a PCA (Karl and Koscielny, 1982). Some chronologies in the network are spatially clustered and highly intercorrelated (e.g., KLL and KLP, IR and ONG), whereas others are isolated and exhibit unique growth patterns. To account for this bias, gridding of tree-ring data has been proposed as an alternative method of identifying spatial patterns of tree-growth anomalies (Meko et al., 1993). Gridding was not appropriate for this dataset due to large gaps within the network. However, we addressed potential biases in the original PCA by applying an additional RPCA to a reduced dataset. We identified chronologies that were visually clustered and highly correlated. A single time series was produced for each cluster by combining the correlated chronologies with an unrotated PCA and extracting the PC1 scores. Then, an RPCA was applied to the reduced dataset (consisting of single chronologies and clusters) following the methods described for the full network analysis.

\section{Evaluating the hydroclimatic signal}

The last objective was to determine if the tree-growth anomalies from the full common period and full network RPCA reflect spatial variability in hydroclimate across the study area. We ran multiple correlation analyses between the regional growth-anomalies (i.e., PC1 scores) and instrumental data. The growth anomaly of each region was compared against the averaged June-August values 


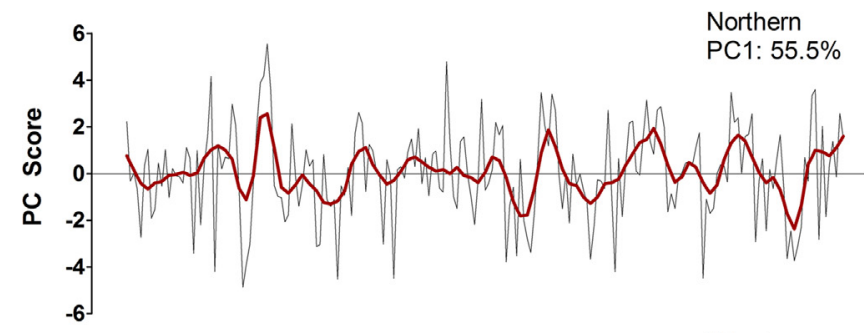

Western

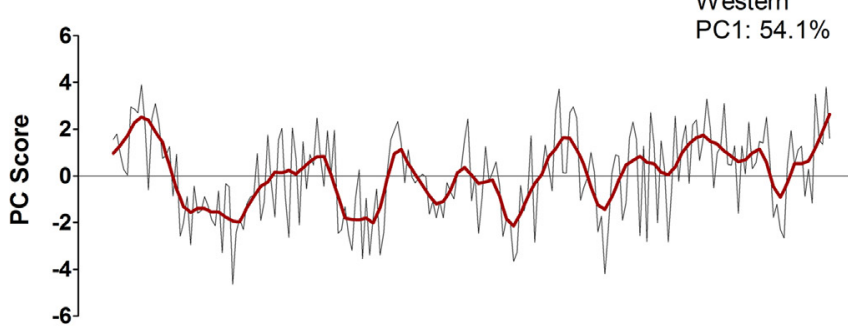

Eastern

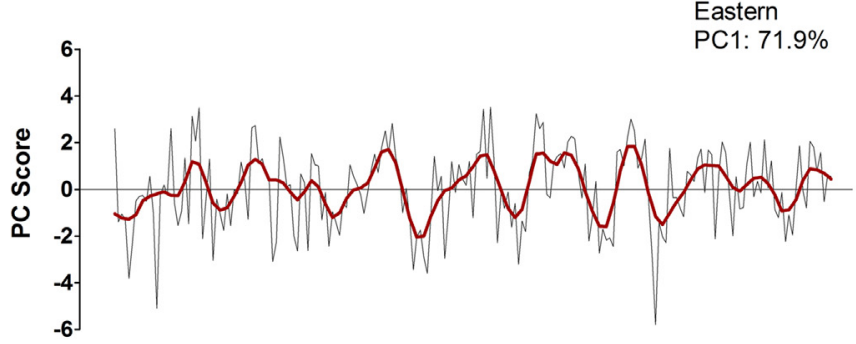

Central

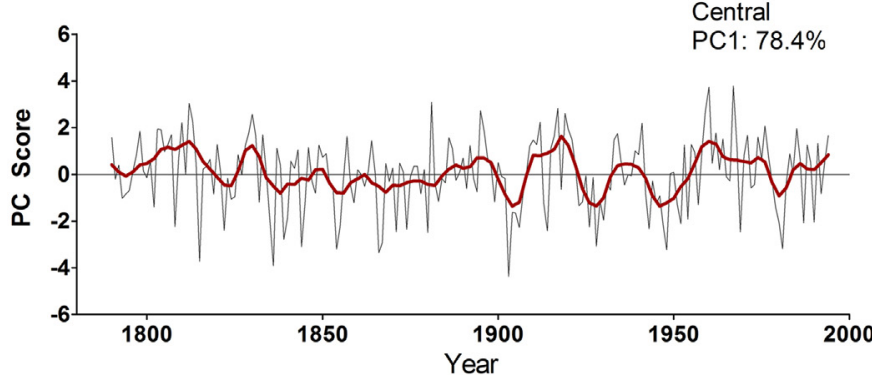

Fig. 3. PC1 scores for each region. Positive PC scores represent above-average growth and negative PC scores indicate below-average growth. The percent variance explained by the leading component for each region is displayed. The bold red lines are an 11-year lowess smoothing curve of each time-series. (For interpretation of the references to color in figure legend, the reader is referred to the web version of the article.)

for each year of the streamflow data (Selenge, Yeruu, and Kherlen Rivers). We considered only the summer months in order to capture the majority of the growing season. The comparisons were restricted to 1959-1994, as the Yeruu and Kherlen River streamflow data extended back only to 1959.

\section{Results}

\section{Regionalization}

After applying an RPCA to all 20 chronologies in the network for the common period 1790-1994, four varimax factors explain a cumulative $63 \%$ of the variance in the dataset. In plotting the chronology loadings of each varimax factor on a map (Fig. 2, Table 2), it is apparent that the factors are divided into four treegrowth anomaly regions: Northern (VF1), Western (VF2), Eastern (VF3), and Central (VF4). All regions consist of at least two different species, except for the Northern region, which is comprised of only $P$. sylvestris. We did not depict negative loadings on the map as
Table 2

Varimax factor loadings from the full period RPCA (1790-1994).

\begin{tabular}{lrrrr}
\hline Chronology & VF1 & \multicolumn{1}{c}{ VF2 } & \multicolumn{1}{c}{ VF3 } & \multicolumn{1}{c}{ VF4 } \\
\hline Khorgo Lava Larch & 0.03 & $\mathbf{0 . 8 3}$ & 0.00 & -0.04 \\
Khorgo Lava Pine & 0.06 & $\mathbf{0 . 8 2}$ & -0.02 & 0.05 \\
Zuun Salaa Mod & -0.08 & $\mathbf{0 . 8 4}$ & -0.03 & 0.13 \\
Orkhon Gol Hurhree & -0.09 & $\mathbf{0 . 5 5}$ & 0.20 & 0.38 \\
Suulchyin Medee & 0.19 & $\mathbf{0 . 7 2}$ & -0.07 & 0.04 \\
Undur Ulaan & 0.37 & $\mathbf{0 . 5 1}$ & 0.18 & 0.22 \\
Tujin Nars & $\mathbf{0 . 7 9}$ & -0.15 & 0.08 & 0.05 \\
Shaamar Manhan Nars & $\mathbf{0 . 7 6}$ & 0.14 & 0.11 & 0.21 \\
Dulaankhan & $\mathbf{0 . 8 2}$ & -0.02 & 0.13 & 0.07 \\
Delger Khan Uul & $\mathbf{0 . 7 5}$ & 0.07 & -0.05 & 0.03 \\
Zurkh Uul & $\mathbf{0 . 6 4}$ & 0.14 & 0.19 & 0.12 \\
Narstain Davaa & $\mathbf{0 . 5 6}$ & 0.14 & 0.10 & 0.34 \\
Bugant & $\mathbf{0 . 6 8}$ & 0.05 & 0.26 & 0.17 \\
Manzshir Hiid & 0.35 & 0.09 & 0.21 & $\mathbf{0 . 7 2}$ \\
Terelj & 0.23 & 0.14 & 0.26 & $\mathbf{0 . 8 3}$ \\
Zuun Mod & 0.14 & 0.10 & 0.14 & $\mathbf{0 . 8 8}$ \\
Urgun Nars & 0.24 & -0.03 & $\mathbf{0 . 7 3}$ & 0.26 \\
Dadal & 0.18 & 0.06 & $\mathbf{0 . 7 7}$ & 0.06 \\
Inferno Ridge & 0.10 & -0.05 & $\mathbf{0 . 9 0}$ & 0.16 \\
Onon Gol & 0.08 & 0.04 & $\mathbf{0 . 8 6}$ & 0.17 \\
\hline
\end{tabular}

Bolded values indicate the highest loading for each chronology.

they were all near zero. Therefore, there are likely no consistently inverse relationships among the regions from 1790 to 1994.

The Orkhon Gol Hurhree (OGH), Undur Ulaan (UU) and Narstyin Davaa (NTD) chronologies do not exhibit a particularly strong favor toward one region. In the case of OGH and $\mathrm{UU}$, this is probably related to their isolated location relative to the other chronologies. OGH loads slightly higher with the Western region compared to the Central region (factor loadings of 0.55 and 0.38 , respectively), therefore we include it with the Western region. Similarly, UU loads higher with the Western region $(0.51)$ versus the Northern region (0.37). The NTD varimax factor loadings for the Northern and Central regions are also similar ( 0.56 and 0.34 , respectively). We include NTD with the Northern region as it loads slightly higher with that tree-growth anomaly.

The regional time series, as determined by the PC1 scores for each region, illustrate variability associated with the four dominant tree-growth anomalies in the network. In comparing pairs of regional time series, the Northern and Central regions are the most highly correlated, and the Western region is the most statistically unique from all of the others (Table 3 ).

\section{Stability analysis}

\section{Temporal subsets}

Both the early (1790-1891) and late (1892-1994) period RPCAs (Figs. 4 and 5 and Table $4 \mathrm{a}$ and b, respectively) exhibit a similar spatial patterning of factors (i.e., tree-growth anomaly regions) as the full period. The early period (1790-1891), however, is the most different in that five components are retained, in which the varimax-rotated factors explain a cumulative $68 \%$ of the variance. The most notable difference is that the Northern region of the full period splits into two separate factors (VF3 and VF5) during the

Table 3

Correlations between all possible pairs of tree-growth anomaly regions.

\begin{tabular}{lllll}
\hline Regions & Eastern & Western & Northern & Central \\
\hline Eastern & - & & & \\
Western & 0.09 & - & & \\
Northern & $0.35^{*}$ & $0.19^{*}$ & - & - \\
Central & $0.44^{*}$ & $0.30^{*}$ & $0.46^{*}$ & - \\
\hline
\end{tabular}

* The correlation coefficient is significant at the $p<0.05$ level. 

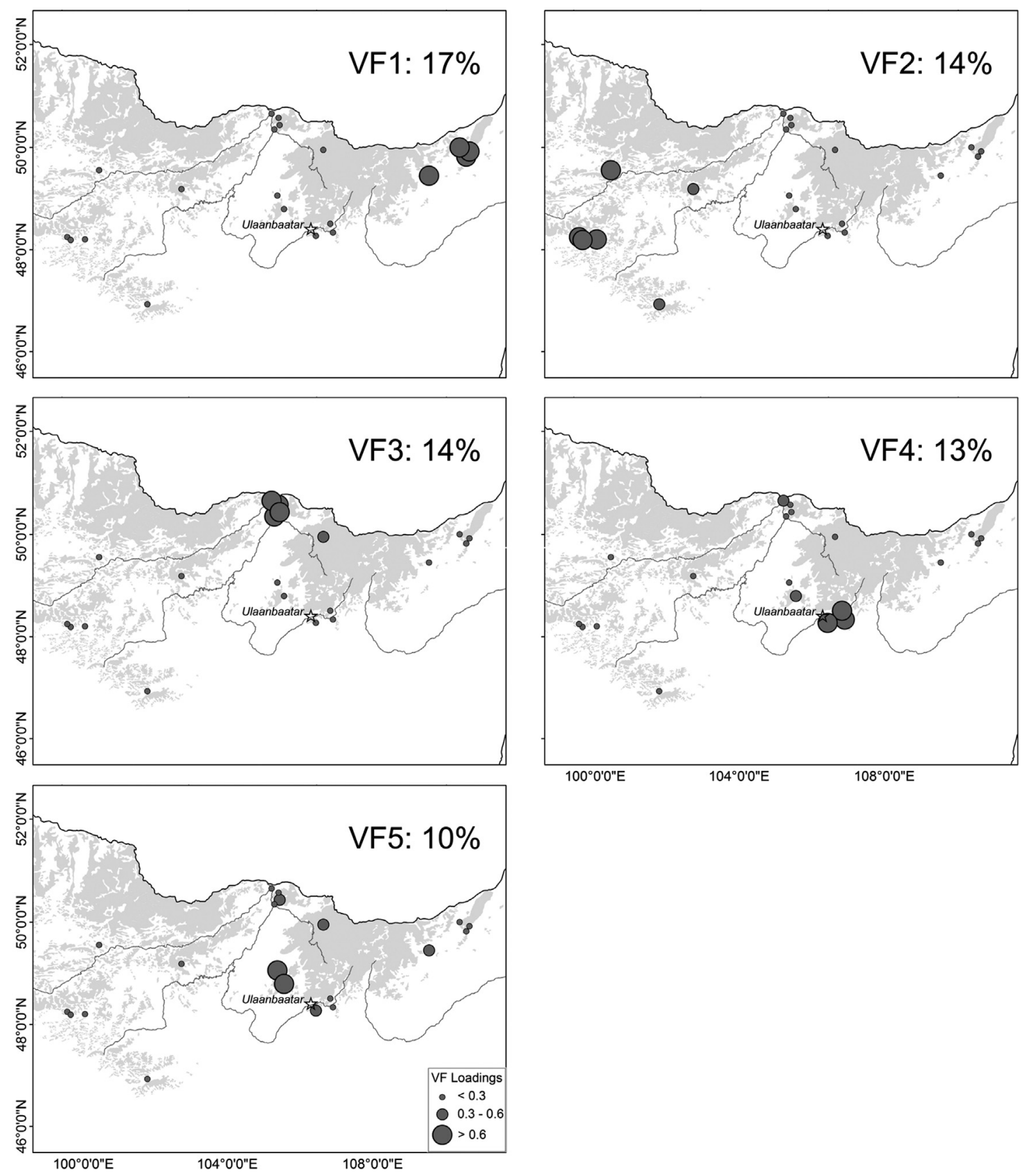

Fig. 4. Maps showing loadings from the five varimax factors over the early period (1790-1891).

early period. However, the chronologies loading highest onto the Eastern, Western, and Central regions of the full period analysis remain the same. Interestingly, the late period (1892-1994) RPCA results are more comparable to the full period RPCA. Four components (eigenvalue $>1$ ) were retained for a varimax rotation in the late period and the four rotated factors explain a cumulative $69 \%$ of the variance in the dataset. Based on the spatial distribution of loadings, the four varimax factors of the late period correspond to the regions identified in the full common period analysis (Eastern, Western, Northern and Central) and nearly all of the chronologies load the highest on the same respective regions as in the full period. The only exception is Undur Ulaan (UU), which does not load the highest on the Western region as in the full period analysis, but rather loads equally as high on the Central (0.46) and Northern (0.46) regions.

\section{Reduced dataset}

We identified four clusters in the network of tree-ring chronologies with a visual inspection of the map (cluster $1=\mathrm{KLL} / \mathrm{KLP} / \mathrm{ZSM}$; cluster $2=\mathrm{SMN} / \mathrm{TNC} / \mathrm{DKH} / \mathrm{DKN}$; cluster $3=\mathrm{TJ} / \mathrm{ZM} / \mathrm{MH}$; cluster $4=\mathrm{DR} / \mathrm{ONG} / \mathrm{IR})$. The chronologies in each cluster are highly correlated with one another $(r \geq 0.5$, but often $r>0.6$ or $0.7 ; p<0.05)$ which statistically validates the cluster assignments. A single time series was produced for each of the four clusters by applying an unrotated PCA to the grouped chronologies and extracting the leading component scores. The scores, summarizing each of the four clusters, were placed into an RPCA with the additional seven (single) chronologies.

After conducting an RPCA of the 11 series, three components were retained (Table 5 ) accounting for a cumulative $65 \%$ of the variance in the reduced dataset. The three varimax factors correspond 

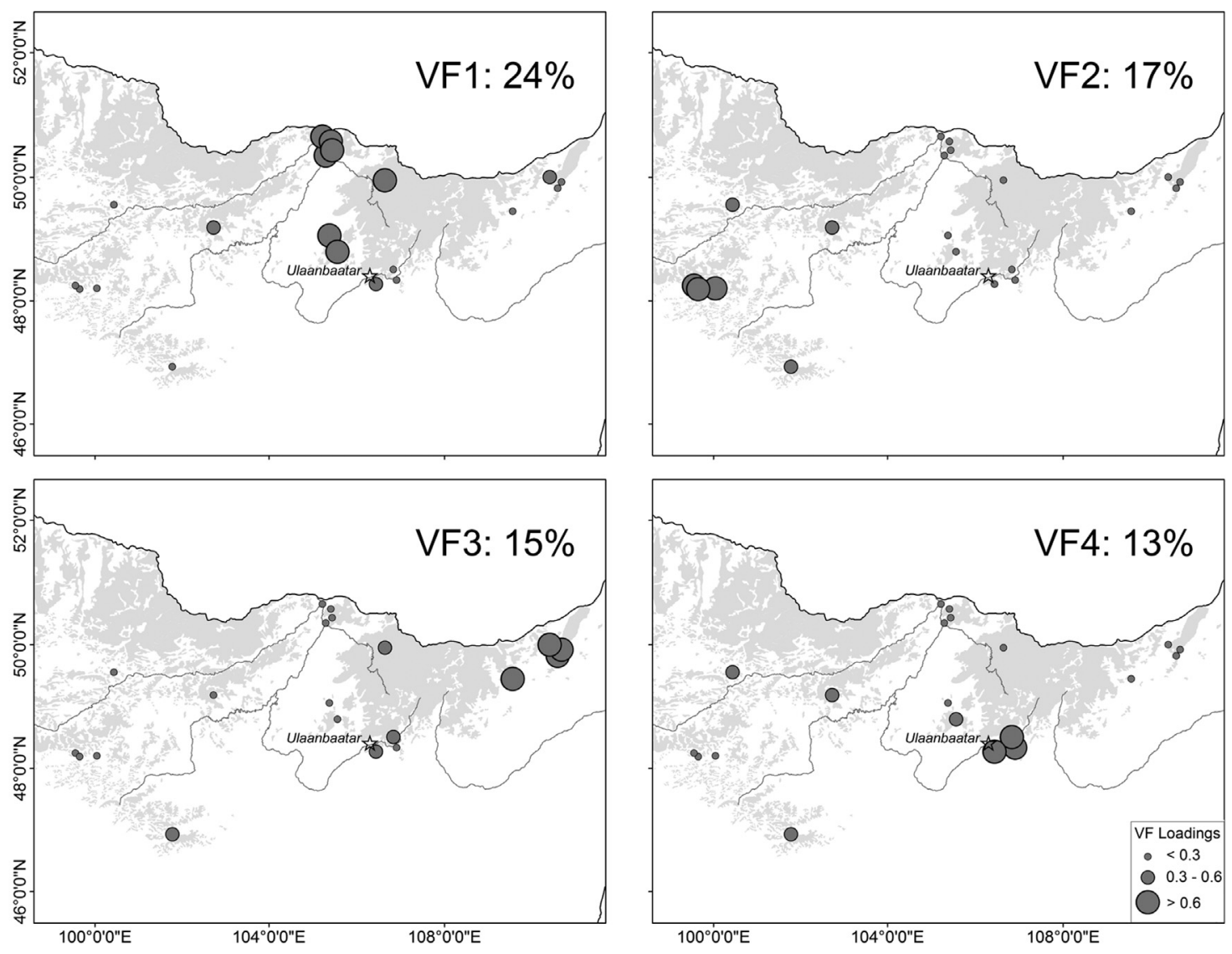

Fig. 5. Maps showing loadings from the four varimax factors over the late period (1892-1994).

to the Eastern, Northern, and Western regions of the full dataset. The cluster of chronologies within the Central region (MH, TJ, ZM) does not produce its own component in the reduced dataset analysis at the eigenvalue $>1$ cut-off criterion. This cluster instead loads highest with the Eastern region (0.57) followed by the Northern region (0.39).

\section{Comparison with instrumental data}

Correlation analyses indicate that there are statistically significant relationships between the regional tree-growth anomalies and instrumental data from 1959 to 1994 (Table 6). In many cases, a single growth-anomaly is strongly correlated with multiple streamflow records across the network; however, the correlations generally decline as a function of increasing distance between the streamflow gauge and tree-growth anomaly region.

The Eastern region did not correlate significantly with any of the streamflow data, though its highest correlation was tied between the Kherlen and Yeruu Rivers (both $r=0.31, p>0.05$ ), while it shared no relationship with the Selenge data $(r=0.07$, $p>0.05)$. Conversely, the Western region correlated significantly with all of the streamflow data presented in this study, though it marginally correlated the highest with the westernmost river in the network (Selenge River; $r=0.56, p<0.05$ ). The Northern growth anomaly was the most associated with the Yeruu River $(r=0.64, p<0.05)$, whereas the Central growth anomaly correlated the highest with the Kherlen River $(r=0.52$, $p<0.05)$.

\section{Extreme hydroclimatic events}

The relationship between tree-growth anomalies and hydroclimate suggests that the marker years of each tree-growth anomaly (or the lowest scores of each component) could be indicators of drought in each region. We ranked the lowest 20 component scores (on a three-year running adjacent-average) in order to determine the most severe periods of reduced growth (Fig. 6), and graphed the rankings in a manner similar to Woodhouse (2001).

In comparing the four tree-growth anomaly regions, some potential periods of drought (i.e., periods of low component scores) are coherent across all or some regions while other periods of severe drought are unique to single regions. The mid-to-late 1970s was a period of reduced growth for all of the regions, but was particularly harsh in the Northern and Central regions. All of the streamflow records also indicate lower than average flow values at that time. Other periods of potential drought across all regions include the early-1900s and the mid-to-late-1920s. In contrast, there are periods of time in which only one or two regions express severely reduced growth. The most noticeable example of this is during the 1800s, in which the Western region (composed of five chronologies) experienced a long-term event of reduced growth ( 1855-1865) that was unparalleled in other regions.

\section{Discussion}

Using a network of 20 tree-ring chronologies, we found four distinct hydroclimatic regions in central Mongolia, a region that is well-populated, important for agriculture, and has not yet been fully studied from a paleoclimatic perspective. Considering that chronologies with different characteristics (i.e., species 

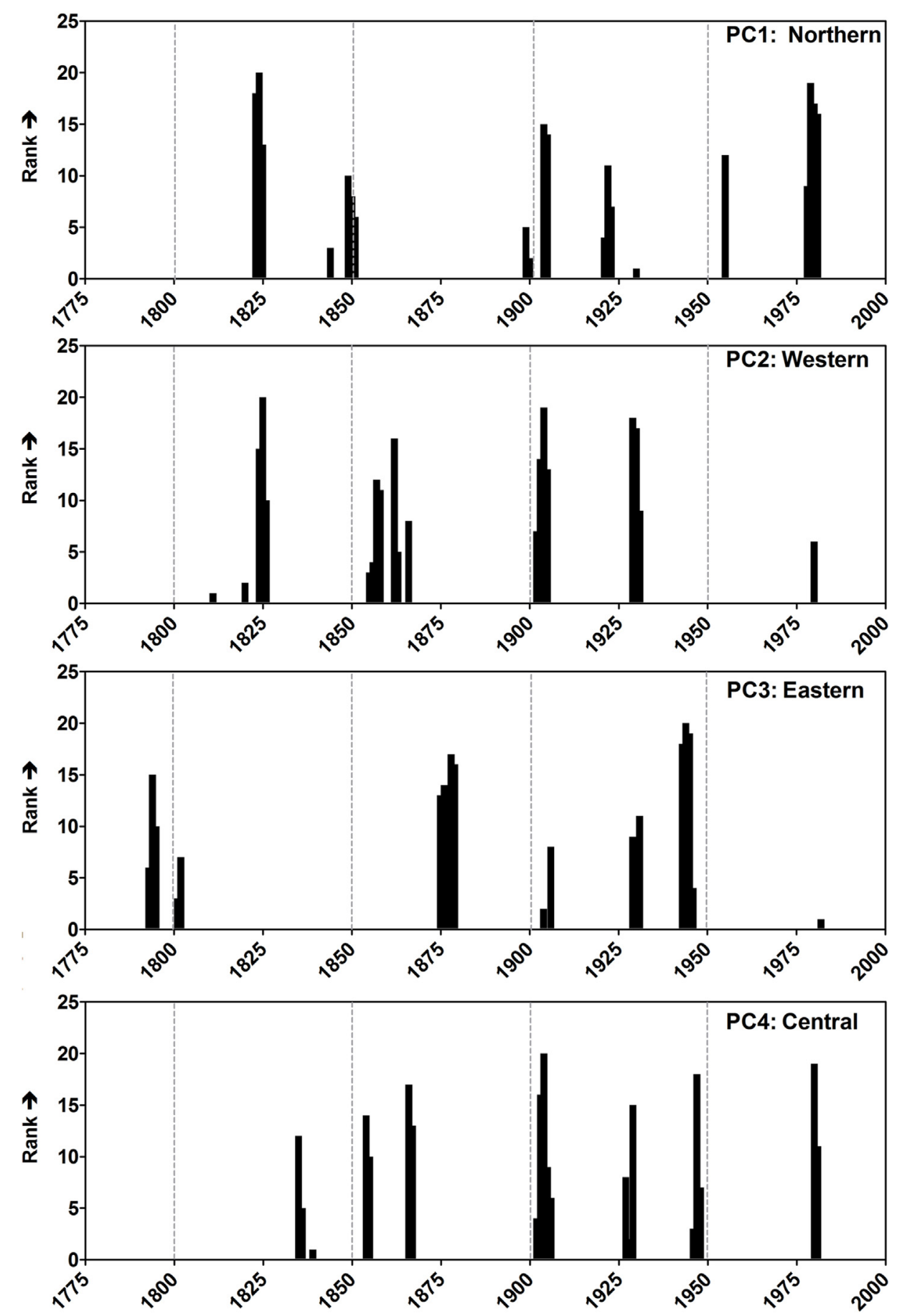

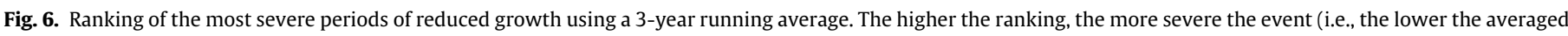
PC1 component scores).

representation, elevation, forest histories, etc.) are associated with the same tree-growth anomaly region suggests that a larger-scale force is influencing the regional tree-growth patterns. Similar to the results of other studies (e.g., Brubaker, 1980; Meko et al., 1993; Watson and Luckman, 2001), our work shows that the spatial patterns of tree-growth anomalies likely reflect hydroclimatic variability across the network.

\section{Tree-growth anomalies}

The four tree-growth anomaly regions display distinct growth patterns over time, although all regions are generally correlated with one another. The Western region was the most dissimilar from other regions, as it had much weaker correlations with other tree-growth anomalies across the study area. The uniqueness 
Table 4

Varimax factor loadings from the (a) early period RPCA (1790-1891) and (b) late period RPCA (1892-1994).

\begin{tabular}{lrrrrr}
\hline (a) & \multicolumn{1}{c}{ VF2 } & \multicolumn{1}{c}{ VF4 } & \multicolumn{1}{c}{ VF5 } \\
\hline Chronology & \multicolumn{1}{c}{ VF1 } & \multicolumn{1}{c}{ VF2 } & & & \\
\hline Khorgo Lava Larch & -0.08 & $\mathbf{0 . 8 1}$ & -0.06 & -0.12 & 0.18 \\
Khorgo Lava Pine & -0.12 & $\mathbf{0 . 7 7}$ & -0.03 & -0.01 & 0.08 \\
Zuun Salaa Mod & -0.19 & $\mathbf{0 . 8 1}$ & -0.05 & 0.09 & -0.10 \\
Orkhon Gol Hurhree & 0.02 & $\mathbf{0 . 5 2}$ & -0.23 & 0.28 & 0.12 \\
Suulchyin Medee & -0.01 & $\mathbf{0 . 8 0}$ & 0.11 & -0.02 & -0.05 \\
Undur Ulaan & 0.29 & $\mathbf{0 . 5 9}$ & 0.28 & 0.24 & 0.02 \\
Tujin Nars & 0.05 & -0.15 & $\mathbf{0 . 8 6}$ & 0.10 & 0.00 \\
Shaamar Manhan Nars & 0.15 & 0.27 & $\mathbf{0 . 7 3}$ & 0.33 & 0.12 \\
Dulaankhan & 0.13 & -0.04 & $\mathbf{0 . 8 0}$ & 0.09 & 0.20 \\
Delger Khan Uul & -0.14 & 0.02 & $\mathbf{0 . 7 0}$ & -0.01 & 0.35 \\
Zurkh Uul & 0.17 & 0.13 & 0.18 & 0.15 & $\mathbf{0 . 8 1}$ \\
Narstain Davaa & 0.23 & 0.13 & 0.14 & 0.33 & $\mathbf{0 . 6 8}$ \\
Bugant & 0.18 & -0.07 & 0.43 & 0.14 & $\mathbf{0 . 6 0}$ \\
Manzshir Hiid & 0.08 & 0.07 & 0.14 & $\mathbf{0 . 7 5}$ & 0.32 \\
Terelj & 0.19 & 0.01 & 0.17 & $\mathbf{0 . 8 7}$ & 0.16 \\
Zuun Mod & 0.12 & 0.06 & 0.10 & $\mathbf{0 . 8 8}$ & 0.05 \\
Urgun Nars & $\mathbf{0 . 6 4}$ & -0.25 & 0.11 & 0.14 & 0.32 \\
Dadal & $\mathbf{0 . 7 6}$ & -0.01 & 0.01 & 0.05 & 0.11 \\
Inferno Ridge & $\mathbf{0 . 8 9}$ & -0.08 & 0.10 & 0.14 & 0.06 \\
Onon Gol & $\mathbf{0 . 8 5}$ & 0.01 & 0.02 & 0.12 & 0.09 \\
& & & & &
\end{tabular}

(b)

\begin{tabular}{lrrrr}
\hline Chronology & \multicolumn{1}{c}{ VF1 } & VF2 & \multicolumn{1}{c}{ VF3 } & \multicolumn{1}{c}{ VF4 } \\
\hline Khorgo Lava Larch & 0.07 & $\mathbf{0 . 8 9}$ & 0.09 & -0.06 \\
Khorgo Lava Pine & 0.13 & $\mathbf{0 . 8 5}$ & 0.05 & 0.10 \\
Zuun Salaa Mod & -0.05 & $\mathbf{0 . 8 6}$ & 0.11 & 0.19 \\
Orkhon Gol Hurhree & -0.04 & $\mathbf{0 . 5 0}$ & 0.34 & 0.42 \\
Suulchyin Medee & 0.29 & $\mathbf{0 . 5 3}$ & -0.19 & 0.37 \\
Undur Ulaan & $\mathbf{0 . 4 6}$ & 0.32 & 0.02 & $\mathbf{0 . 4 6}$ \\
Tujin Nars & $\mathbf{0 . 8 2}$ & -0.10 & 0.21 & 0.03 \\
Shaamar Manhan Nars & $\mathbf{0 . 8 3}$ & 0.06 & 0.24 & 0.14 \\
Dulaankhan & $\mathbf{0 . 8 4}$ & -0.04 & 0.13 & 0.16 \\
Delger Khan Uul & $\mathbf{0 . 7 3}$ & 0.16 & 0.10 & 0.07 \\
Zurkh Uul & $\mathbf{0 . 7 6}$ & 0.06 & 0.07 & 0.08 \\
Narstain Davaa & $\mathbf{0 . 6 5}$ & 0.08 & -0.10 & 0.38 \\
Bugant & $\mathbf{0 . 7 1}$ & 0.19 & 0.33 & 0.09 \\
Manzshir Hiid & 0.39 & 0.08 & 0.39 & $\mathbf{0 . 6 0}$ \\
Terelj & 0.18 & 0.24 & 0.42 & $\mathbf{0 . 7 3}$ \\
Zuun Mod & 0.12 & 0.08 & 0.25 & $\mathbf{0 . 8 5}$ \\
Urgun Nars & 0.26 & 0.13 & $\mathbf{0 . 7 3}$ & 0.30 \\
Dadal & 0.33 & 0.10 & $\mathbf{0 . 7 0}$ & 0.14 \\
Inferno Ridge & 0.08 & 0.01 & $\mathbf{0 . 9 4}$ & 0.08 \\
Onon Gol & 0.10 & 0.03 & $\mathbf{0 . 8 8}$ & 0.19 \\
\hline
\end{tabular}

The bolded values indicate the highest loading for each chronology.

of the Western region, in particular, might be attributable to orographic effects. The Western region is located in the Khangai Mountain range and is generally higher in elevation, whereas the other regions to the east are more closely associated with the Khentyi Mountain range or are at the northern edge of the Gobi steppe.

Table 5

Varimax factor loadings from the reduced dataset PCA.

\begin{tabular}{lrrr}
\hline Chronology/cluster & VF1 & VF2 & VF3 \\
\hline KLL/KLP/ZSM & 0.00 & $\mathbf{0 . 8 2}$ & -0.01 \\
SM & 0.20 & $\mathbf{0 . 8 0}$ & -0.15 \\
UU & 0.43 & $\mathbf{0 . 6 2}$ & 0.13 \\
OGH & -0.11 & $\mathbf{0 . 6 7}$ & 0.41 \\
SMN/TNC/DKH/DKN & $\mathbf{0 . 7 9}$ & 0.04 & 0.13 \\
BG & $\mathbf{0 . 7 4}$ & 0.02 & 0.27 \\
ZHU & $\mathbf{0 . 7 6}$ & 0.11 & 0.15 \\
NTD & $\mathbf{0 . 7 6}$ & 0.15 & 0.13 \\
TJ/ZM/MH & 0.39 & 0.29 & $\mathbf{0 . 5 7}$ \\
UN & 0.26 & -0.05 & $\mathbf{0 . 8 3}$ \\
DR/ONG/IR & 0.16 & 0.01 & $\mathbf{0 . 8 6}$ \\
\hline
\end{tabular}

The bolded values indicate the highest loading for each chronology.
Table 6

Correlations between streamflow data and regional PC1 scores over the period 1959-1994.

\begin{tabular}{lllll}
\hline River & Eastern & Western & Northern & Central \\
\hline Selenge & 0.07 & $0.56^{*}$ & $0.52^{*}$ & 0.18 \\
Yeruu & 0.31 & $0.52^{*}$ & $0.64^{*}$ & $0.34^{*}$ \\
Kherlen-Underkhaan & 0.31 & $0.53^{*}$ & $0.45^{*}$ & $0.52^{*}$ \\
\hline
\end{tabular}

The correlation coefficient is significant at the $p<0.05$ level.

Studies have emphasized that the Khangai and Khentyi mountain ranges are climatically different, in terms of both cloud frequency (Sato et al., 2004), and summer precipitation patterns (Kim et al., 2011). Li et al. (2009) also identified strong regional differences in moisture variability between far western/central Mongolia and Eastern Mongolia. The findings from these studies support the strong differences between the Eastern and Western tree-growth anomalies that were found here.

All tree-growth anomaly regions remained mostly consistent during the early and late temporal subsets, except for the Northern region, which split into two separate regions during the early period (1790-1891). The instability of the Northern region is not particularly surprising considering that this region encompasses the transitional area between the more forested area of far Northern Mongolia and the drier steppe region further south. Interestingly, a temporal subset analysis with the residual chronologies resulted in a greater overall stability of the Northern region during the early period but a separation of the Western region into two separate sub-regions (KLL/KLP/ZSM and SM/UU) (Leland, 2011). These results are not entirely unexpected because other studies have suggested that the period of analysis could influence the locations or numbers of regions identified by an RPCA (Meko et al., 1993). In this case, it is possible that an additional component in the early period could reflect a natural shift in precipitation patterns that resulted in two unique tree-growth anomalies within the Northern region. For example, Watson and Luckman (2001) suggested that changes in tree-growth anomaly sub-regions over time in the Southern Canadian Cordillera could be attributed to temporal changes in large-scale atmospheric circulation anomalies. Circulation anomalies influencing precipitation in central Mongolia are complex. Potential influence from synoptic-scale disturbances, such as the Asian summer monsoon (Sato et al., 2007b) and the ElNino Southern Oscillation (Davi et al., 2010) are dynamic and could directly affect the instability of the regions over time. Further analyses are required to evaluate potential synoptic-scale disturbances that might be influencing the network. These temporal stability findings could also have implications for developing reliable climate reconstructions, and might be taken into consideration when deciding which potential predictor chronologies co-vary consistently over time and exist in a time-stable 'region' (see Pederson et al., 2012 for an example of this application).

In testing the influence of chronology clusters in the reduced dataset analysis, results suggest that the tree-growth anomaly regions remain fairly consistent over the common period (1790-1994) after chronology clusters are removed. It was expected that the Central region's importance might decline in the reduced dataset RPCA considering we condensed the entire region to only one variable. However, the importance of the Central region might have been elevated due to the clustering of the three central chronologies in the full dataset ( $\mathrm{MH}, \mathrm{TJ}$, and $\mathrm{ZM})$. This finding does not discount the significance of this region in the network; the Central region remains distinct considering the Central cluster does not load particularly high with any of the other regions. The regional time series and extreme events analysis also suggest 
that the Central region represents a unique climatic area within the network.

While the stability analyses highlight the robustness of the treegrowth anomaly regions, it should be noted that these results could be a by-product of the spatial scale of the study. A change in the spatial extent of the study area, or the number of chronologies in the network, could potentially change the bounds or number of tree-growth anomaly regions identified by an RPCA. The variation in tree-growth anomalies is a continuous phenomenon across the landscape and the RPCA only identifies the most representative tree-growth anomalies from the chronologies that are available. Nonetheless, the tree-growth anomalies identified herein are an important foundation for assessing broad-scale growth patterns across central Mongolia. In future studies, they could be valuable for understanding the influences of atmospheric forcings on regional and local spatial scales.

\section{Hydroclimate analysis and extreme events}

Spatial distinctions of the tree-growth anomaly regions were not as evident in comparisons with streamflow data. The treegrowth anomalies always correlated the highest with streamflow data nearest to their respective regions, however, some relative differences in correlations were not logical from a spatial perspective. For example, the Kherlen streamflow gauge at Underkhaan marginally correlated the highest with the Western region in comparison to all other regions, which was located the farthest away. Even though the correlations between the tree-growth anomaly regions and the streamflow data are mostly logical from a spatial perspective, the spatial relationships might have been stronger if the streamflow records extended further back in time. This is likely the case because many of the obvious differences between the tree-growth anomalies occurred prior to the common period of instrumental records.

Regional differences seen in the analyses above are supported when ranking extreme hydroclimatic events through time, which highlight the regional nature of severe droughts (Fig. 6). Results from the Eastern and Western regions essentially mimic the findings of the Kherlen and Selenge hydroclimatic reconstructions, respectively (Pederson et al., 2001; Davi et al., 2006). Despite a substantial increase in chronology replication across central Mongolia relative to the Pederson et al. (2001) and Davi et al. (2006) studies, these results are expected considering that some of the chronologies incorporated here were also used in developing the Kherlen and Selenge reconstructions. As discussed in the Davi et al. (2006) study, the most prominent regional difference between the Selenge and Kherlen River reconstructions took place during the late 1700s. The Western region (Selenge) was wet, whereas the Eastern region (Kherlen) was dry. While our analysis extends back only to 1790 , this trend is still apparent (Fig. 3). More importantly, the ranking results presented here emphasize the distinctive nature of the Northern and Central regions, which have recently been considered in other studies due to our findings (Pederson et al., 2012; Saladyga et al., in preparation). The Northern and Central regions share some periods of reduced growth with other regions in the network, most notably in the early 1900s and the late 1970s. Differences arise around 1850 and in the early 1920s, when only the Northern region expresses severely reduced growth. These important drought periods are evident in a recently published reconstruction of the Yeruu River in Northcentral Mongolia (Pederson et al., 2012). Similarly, the Central region has no extreme events from $\sim 1790$ to 1834 , a pattern that is not found in the other regions. The regional rankings of extreme hydroclimatic events further supports some spatial variability in drought patterns and emphasizes the importance of multiple climate reconstructions across the network.

\section{Conclusion}

This study introduces four tree-growth anomaly regions across central Mongolia based on a network of 20 tree-ring chronologies. A temporal subset and reduced dataset analysis both indicate that these regions are mostly stable. Further, the tree-growth anomalies exhibit a statistically significant relationship with instrumental climate variables, suggesting that they are reflections of hydroclimatic variability across the network. Results here show that a network of chronologies is an important means of evaluating regional hydroclimatic variability, particularly in locations where instrumental records are spatially and temporally limited. It is likely that the tree-growth anomalies identified in the Northern and Central regions of this study are climatically distinct. Therefore, there has recently been great potential in developing hydroclimatic reconstructions for these two regions in the network. The tree-growth anomalies discussed here are a foundation for placing hydroclimatic variability in a spatiotemporal context. Future studies should focus on the potential mechanisms and forcings behind hydroclimatic variability in the four tree-growth anomaly regions across central Mongolia.

\section{Acknowledgments}

This research was funded by the National Science Foundation (Grant No. DEB-0816700). We would like to thank our Mongolian colleagues and those from the tree-ring lab at Lamont-Doherty Earth Observatory for providing helpful guidance and expertise. Specifically, we would like to thank E. Cook, B. Suran, U. Ariya, and T. Saladyga. Lamont-Doherty Earth Observatory Contribution Number XXXX.

\section{References}

Batima, P., Natsagdorj, L., Gombluudev, P., Erdenetsetseg, B., 2005. Observed climate change in Mongolia. Assessments and Adaptations to Climate Change (AIACC) Working Paper 12, 1-26.

Brubaker, L.B., 1980. Spatial patterns of tree growth anomalies in the Pacific Northwest. Ecology 61, 798-807.

Buckley, B.M., Anchukaitis, K.J., Penny, D., Fletcher, R., Cook, E.R., Sano, M., Nam, L.C. Wichienkeeo, A., Minh, T.T., Hong, T.M., 2010. Climate as a contributing factor in the demise of Angkor, Cambodia. Proceedings of the National Academy of Sciences of the United States of America 107, 6748-6752.

Christensen, J.H., Hewitson, B., Busuioc, A., Chen, A., Gao, X., Held, I., Jones, R., Kolli, R.K., Kwon, W.T., Laprise, R., Magaña Rueda, V., Mearns, L., Menéndez, C.G., Räisänen, J., Rinke, A., Sarr, A., Whetton, P., 2007. Regional climate projections. In: Solomon, S., Oin, D., Manning, M., Chen, Z., Marquis, M., Averyt, K.B., Tignor, M. Miller, H.L. (Eds.), Climate Change 2007: The Physical Science Basis. Contribution of Working Group I to the Fourth Assessment Report of the Intergovernmental Panel on Climate Change. Cambridge University Press, Cambridge, United Kingdom and New York, NY, USA, pp. 847-940.

Cook, E.R., 1985. A time-series analysis approach to tree-ring standardization. In: Dissertation. The University of Arizona Press, Tucson.

Cook, E.R., Kairiukstis, L.A. (Eds.), 1990. Methods of Dendrochronology: Applications in the Environmental Science. Kluwer Academic Publ, Hingham, MA, p. 480.

Cook, E.R., Krusic, P.J., 2011. Software. Tree Ring Laboratory of Lamont-Doherty Earth Observatory http://www.ldeo.columbia.edu/tree-ring-laboratory/ resources/software (accessed 10.07.11)

Cook, E.R., Peters, K., 1981. The smoothing spline: a new approach to standardizing forest interior tree-ring width series for dendroclimatic studies. Tree-Ring Bulletin 41, 45-53.

Cook, E.R., Peters, K., 1997. Calculating unbiased tree-ring indices for the study of climatic and environmental change. Holocene 7, 361-370.

Cook, E.R., Meko, D.M., Stahle, D.W., Cleaveland, M.K., 1999. Drought reconstructions for the continental United States. Journal of Climate 12, 1145-1162.

Dai, A., Trenberth, K.E., Qian, T., 2004. A global dataset of Palmer drought severity index for 1870-2002: relationship with soil moisture and effects of surface warming. American Meteorological Society 5, 1117-1130. 
Davi, N.K., Jacoby, G.C., Curtis, A.E., Baatarbileg, N., 2006. Extension of drought records for central Asia using tree-rings: west-central Mongolia. Journal of Climate 19, 288-299.

Davi, N.K., Jacoby, G.C., D’Arrigo, R., Baatarbileg, N., Jinbao, L., Curtis, A.E., 2009 A tree-ring-based drought index reconstruction for far-western Mongolia: 1565-2004. International Journal of Climatology 29, 1508-1514.

Davi, N., Jacoby, G.C., Fang, K., Li, J., D’Arrigo, R., Baatarbileg, N., Robinson, D., 2010. Reconstructing drought variability for Mongolia based on large-scale tree-ring network: 1520-1993. Journal of Geophysical Research 115 (D22103), 9.

Endo, N., Kadota, T., Matsumoto, J., Ailikun, B., Yasunari, T., 2006. Climatology and trends in summer precipitation characteristics in Mongolia for the period 1960-1998. Journal of the Meteorological Society of Japan 84, 543-551.

Esper, J., Shiyatov, S.G., Mazepa, V.S., Wilson, R.J.S., Graybill, D.A., Funkhouser, G., 2003. Temperature-sensitive Tien Shan tree-ring chronologies show multicentennial growth trends. Climate Dynamics 21, 699-706.

Fang, K., Davi, N., Gou, X., Chen, F., Cook, E., Li, J., D’Arrigo, R., 2010. Spatial drought reconstructions for central High Asia based on tree rings. Climate Dynamics 35 941-951.

Friedman, J.H., 1984. A variable span smoother. In: Technical Report LCS. Department of Statistics, Stanford University, pp. 5.

Fritts, H.C., 1976. Tree Rings and Climate. Academic Press, New York, pp. 567.

Holmes, R.L., 1983. Computer assisted quality control in tree-ring dating and measurement. Tree-Ring Bulletin 43, 69-78.

Johnson, D.A., Sheehy, D.P., Miller, D., Damiran, D., 2006. Mongolian rangelands in transition. Secheresse 17, 133-141.

Karl, T.R., Koscielny, A.J., 1982. Drought in the United States. Journal of Climatology 2, 313-329.

Kim, B.S., Hossein, S.Z., Choi, G., 2011. Evaluation of temporal-spatial precipitation variability and prediction using seasonal ARIMA Model in Mongolia. KSCE Journal of Civil Engineering 15, 917-925.

LaMarche Jr., V.C., Fritts, H.C., 1971. Anomaly patterns of climate over the western United States, 1700-1930, derived from principal component analysis of treering data. Monthly Weather Review 99, 138-142.

Leland, C., 2011. Hydroclimatic variability in north-central Mongolia as inferred from tree rings. In: Master's Thesis. West Virginia University.

Li, J., Cook, E.R., D'arrigo, R., Chen, F., Gou, X., 2009. Moisture variability across China and Mongolia: 1951-2005. Climate Dynamics 32, 1173-1186.

Lorimer, C.G., Frelich, L.E., 1989. A methodology for estimating canopy disturbance frequency and intensity in dense temperate forests. Canadian Journal of Forest Research 19, 651-663.

Meko, D., Cook, E.R., Stahle, D.W., Stockton, C.W., Hughes, M.K., 1993. Spatial patterns of tree-growth anomalies in the United States and Southeastern Canada. Journal of Climate 6, 1773-1786.

Pederson, N., 2010. External characteristics of old trees in the eastern deciduous forest. Natural Areas Journal 30, 396-407.

Pederson, N., Jacoby, G.C., D’Arrigo, R.D., Cook, E.R., Buckley, B., Dugarjav, C., Mijiddorj, R., 2001. Hydrometeorological reconstructions for northeastern Mongolia derived from tree-rings: 1651-1995. Journal of Climate 14, 872-881.
Pederson, N., Cook, E.R., Jacoby, G.C., Peteet, D.M., Griffin, K.L., 2004. The influence of winter temperatures on the radial growth of six northern range margin tree species. Dendrochronologia 22, 7-29.

Pederson, N., Leland, C., Nachin, B., Hessl, A.E., Bell, A.R., Martin-Benito, D., Saladyga, T., Suran, B., Brown, P.M., Davi, N.K., 2012. Three centuries of shifting hydroclimatic regimes across the Mongolian Breadbasket. Agricultural and Forest Meteorology.

Richman, M.B., 1986. Rotation of principal components. Journal of Climatology 6, 293-335.

Saladyga, T.M., Pederson, N., Hessl, A., Nachin, B., Davi, N., 2013. Tree-ring based drought reconstruction for the Central Khan Khentii Mountains, Mongolia (1675-2000). Chinese Science Bulletin (in preparation).

Sato, T., Kimura, F., Kitoh, A., 2004. Cloud frequency in eastern Mongolia and its relation to orography. In: Proceedings of the Third International Workshop on Terrestrial Change in Mongolia, Ulan Bator, pp. 107-109.

Sato, T., Kimura, F., Kitoh, A., 2007a. Projection of global warming onto regional precipitation over Mongolia using a regional climate model. Journal of Hydrology 333, 144-154.

Sato, T., Tsujimura, M., Yamanaka, T., Iwasaki, H., Sugimoto, A., Sugita, M., Kimura, F., Davaa, G., Oyunbaatar, D., 2007b. Water sources in semiarid northeast Asia as revealed by field observations and isotope transport model. Journal of Geophysical Research - Atmospheres 112, D17112.

Siurua, H., Swift, J., 2002. Drought and zud but no famine (yet) in the Mongolian herding economy. IDS Bulletin 33, 88-97.

Stokes, M.A., Smiley, T.L., 1968. An Introduction to Tree-Ring Dating. The University of Chicago Press, Chicago, pp. 95.

Swetnam, T.W., Brown, P.M., 1992. Oldest known conifers in the southwestern United States: Temporal and spatial patterns of maximum age. In: Kaufmann, M.R., Moir, W.H., Bassett, R.L. (tech. coords.), Old Growth Forests in the Southwest and Rocky Mountain Regions. USDA For. Ser. Gen. Tech. Rep. RM-213, pp. 24-38.

Tebaldi, C., Hayhoe, K., Arblaster, J.M., Meehl, G.A., 2006. Going to the extremes: an intercomparison of model-simulated historical and future changes in extreme events. Climatic Change 76, 185-211.

Trenberth, K.E., Dai, A., Ramussen, R.M., Parsons, D.B., 2003. The changing character of precipitation. Bulletin of the American Meteorological Society 84, 1205-1217.

Watson, E., Luckman, B.H., 2001. The development of a moisture-stressed tree-ring chronology network for the southern Canadian Cordillera. Tree-Ring Research 57, 149-168.

White, D., Richman, M., Yarnal, B., 1991. Climate regionalization and rotation of principal components. International Journal of Climatology 11, 1-25.

Wigley, T.M.L., Briffa, K.R., Jones, P.D., 1984. On the average value of correlated time series, with applications in dendroclimatology and hydrometeorology. Journal of Applied Meteorology 23, 201-213.

Woodhouse, C.A., 2001. A tree-ring reconstruction of streamflow for the Colorado Front Range. Journal of the American Water Resources Association 37, 561-569. 